\title{
Langmuir-Blodgett films of different ionomeric polymers deposited on electrode surfaces
}

\author{
Paolo Ugo ${ }^{*, 1}$, Paolo Bertoncello ${ }^{2}$, Francesca Vezzà \\ Department of Physical Chemistry, University of Venice, Calle Larga Santa Marta 2137, 30123 Venice, Italy
}

Received 20 October 2003; received in revised form 7 January 2004; accepted 7 January 2004

Available online 4 June 2004

\begin{abstract}
This paper shows the possibility to apply the Langmuir-Blodgett (LB) techniques for the preparation of ultrathin films of various ionomeric polymers, namely Nafion ${ }^{\circledR}$ (perfluorinated cation-exchanger), Tosflex ${ }^{\circledR}$ (perfluorinated anion-exchanger) and Eastman AQ55 ${ }^{\circledR}$ (polyestersulfonated cation-exchanger). The pressure-area isotherms and the condensation degree of the interfacial films depend on the chemical structure of the ionomer and on the nature of the electrolyte dissolved in the subphase. The addition of a strong electrolyte to the subphase is, in fact, a compulsory requirement in order to allow the formation of a stable ionomer layer at the air-water interface. The interfacial film can be transferred by LB deposition technique onto substrates such as glassy carbon, gold or indium-tin oxide electrodes. Quartz crystal microbalance data indicate the uniformity of such LB-coatings and ion-exchange voltammetric measurements confirm their ion-exchange preconcentration capabilities. Films based on perfluorinated ionomers such as Nafion ${ }^{\circledR}$ and Tosflex ${ }^{\circledR}$ are characterized by higher condensation degrees and are closer to reach a monolayer packing than films based on the polyestersulfonated Eastman AQ55 ${ }^{\circledR}$.
\end{abstract}

(C) 2004 Elsevier Ltd. All rights reserved.

Keywords: Langmuir-Blodgett; Ionomers; Nafion ${ }^{\circledR}$; Tosflex ${ }^{\circledR}$; Eastman AQ55 ${ }^{\circledR}$; Ion-exchange; Voltammetry

\section{Introduction}

The Langmuir-Blodgett (LB) technique is used extensively to build up monolayers or multilayers of organic amphiphilic molecules in which the order and 2D structure are controlled at the molecular level [1-3]. By this way, it is possible to obtain ultrathin films characterized by long range order, which can provide new insights on electron transfer processes at molecularly ordered interfaces $[4,5]$.

Since 1970s, the use of ionomers has received great attention because of their peculiar properties such as ion-exchange selectivity, good wetting properties, self organization in hydrophobic/hydrophilic domains, chemical and biological inertness [6]. Electrochemical applications

* Corresponding author. Tel.: +39-041-2348503;

fax: +39-041-2348594.

E-mail address: ugo@unive.it (P. Ugo).

1 ISE member.

2 Present address: Department of Chemistry and Biochemistry, The University of Texas at Austin, 1 University Station, MailStop A5300, Austin, TX 78712, USA. of ionomeric polymers include fuel cells [7], chemically modified electrodes [8-10], voltammetric sensors [11-13] and electrochromic devices [14,15].

Among ionomeric polymers, Nafion ${ }^{\circledR}$, Tosflex ${ }^{\circledR}$ and Eastman AQ55 ${ }^{\circledR}$ (briefly, AQ55 hereafter, see Scheme 1) have received particular attention in electroanalysis thanks to the possibility to recast thin films of these polymers on electrode surfaces so obtaining voltammetric microelectrodes useful for preconcentrating and determining trace concentrations of redox ion analytes [11-13].

Notwithstanding the easiness of the coating deposition, films of recasted ionomers show properties strongly dependent on the deposition conditions such as solvent choice, curing temperature or relative humidity during the drying step [16-20]. These evidences indicate that significant improvements in the reliable use of ionomer-coated electrodes can come from the ability to control at a molecular level the deposition. Recent results [15] showed the possibility to obtain LB films of Nafion ${ }^{\circledR}$ at the air-water interface, which can be transferred on electrode surfaces by using the Langmuir-Schaefer (LS) deposition technique. It was also shown that the diffusion coefficients of electroactive 


$$
\begin{aligned}
& -\left(\mathrm{CF}_{2} \mathrm{CF}_{2}\right)_{\mathbf{x}}\left(\mathrm{CFCF}_{2}\right)_{\mathbf{y}^{-}} \\
& \mathrm{O}_{\mathrm{O}}^{-}\left(\mathrm{C}_{3} \mathrm{~F}_{6}\right)-\mathrm{O}-\mathrm{CF}_{2} \mathrm{CF}_{2}-\mathrm{SO}_{3} \mathrm{Na}^{+} \\
& \text {Nafion }
\end{aligned}
$$

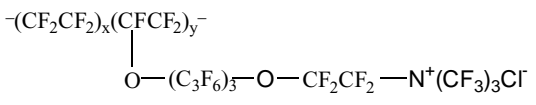

Tosflex IE-SA 48

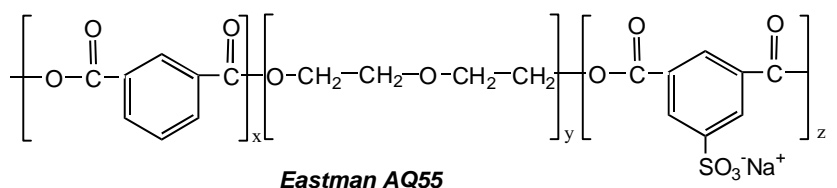

Scheme 1

cation (methylviologen and $\mathrm{Ru}\left(\mathrm{NH}_{3}\right)_{6}{ }^{3+}$ ) incorporated by ion-exchange in Nafion ${ }^{\circledR}$ LS-films are lower than values measured in recasted films [21], so indicating a higher condensation degree for the former coatings.

The LS technique is an horizontal lift technique which usually is employed for the transfer of rigid films of materials such as polymers [2,3]. The substrate touches the monolayer horizontally, than it is inclined and moved up. Although the LS technique showed to work well for Nafion ${ }^{\circledR}$ [15], it has the limitation to rely upon the manual ability and experience of the experimentalist. In the present work we focus on the possibility to deposit Langmuir layers of ionomers by resorting to the Langmuir-Blodgett technique which is a vertical dipping-lift deposition technique for which the rate and extent of the movement of the substrate through the interfacial film is controlled automatically by using a mechanical dipper driven by suitable software. Another goal is to try to demonstrate the general applicability of the LB technique to different ionomeric polymers $\left(\right.$ Nafion $^{\circledR}$, Tosflex ${ }^{\circledR}$, AQ55). The LB technique shows to be a good alternative for the preparation of ionomer-coated electrodes with the possibility to control the structure and properties of the modified electrode at a molecular level.

\section{Materials and methods}

\subsection{Chemicals}

Nafion ${ }^{\circledR} 117$ solution (equivalent weight (EW) 1100, $5 \% \mathrm{w} / \mathrm{v}$ in a mixture of low molecular weight alcohol) was purchased from Sigma-Aldrich. Tosflex ${ }^{\circledR}$ IESA 48 was purchased some years ago as thick membrane from Tosoh Soda Manifacturing, Kanagawa, Japan. Samples of Eastman AQ55 ${ }^{\circledR}$ pellets were a kind gift from Eastman-Italy. All other chemicals were of reagent grade quality.
Stock solutions of Nafion ${ }^{\circledR}$ at the required concentration were prepared by proper dilution of the commercial solution with methanol.

Tosflex ${ }^{\circledR}$ IESA 48 (EW 1859 [22]) solution was prepared dissolving finely cut pieces of the Tosflex membrane by extended reflux in a mixture of ethanol/isopropanol/water in 1:1:1 ratio, according to the procedure described in literature [23]. The resulting solution $(2.5-3 \% \mathrm{w} / \mathrm{v})$ was then diluted to the required concentration by addition of methanol.

Water dispersions of Eastman AQ55 ${ }^{\circledR}$ (EW 1300-1500 $[16,24,25])$ were prepared following published procedures [25]; briefly, $15 \mathrm{~g}$ of finely ground AQ55 powder were dispersed in $100 \mathrm{~mL}$ of water and kept under vigorous and extended stirring at $45^{\circ} \mathrm{C}$ until a transparent and colorless solution was obtained. It was cooled at room temperature and filtered. The concentration of the solution was measured by weighing and drying a known volume of the dispersion. Eventual dilution to the required concentration was carried out by adding proper volume of a water/ acetone mixture in $1: 1$ ratio.

(Ferrocenylmethyl)dimethylamine (Aldrich) was reacted with methyl iodide to form the quaternary ammonium iodide [26]. This was then converted to (ferrocenylmethyl)-trimethylammonium hexafluorophosphate $\left(\mathrm{FA}^{+} \mathrm{PF}_{6}{ }^{-}\right)$using $\mathrm{AgPF}_{6}$.

\subsection{Preparation of LB films}

Langmuir interfacial films of ionomers were formed by using a Langmuir trough (Langmuir KSV 2000 trough, KSV Instruments Ltd., Finland) interfaced with a PC and controlled by its software (KSV LB WIN 1.22 version). The surface pressure was measured by means of a Wilhemy balance with an accuracy of $0.2 \mathrm{mN} \mathrm{m}^{-1}$.

The concentration and volume of the ionomer solutions added to $1 \mathrm{~L}$ of the subphase were:

- $300 \mu \mathrm{L}$ of $0.5 \mathrm{mg} \mathrm{mL}^{-1} \mathrm{Nafion}^{\circledR}$ solution (diluted with methanol);

- $200 \mu \mathrm{L}$ of $0.5 \mathrm{mg} \mathrm{mL}^{-1}$ Tosflex $^{\circledR}$ solution (diluted with methanol);

- $400 \mu \mathrm{L}$ of $0.075 \mathrm{mg} \mathrm{mL}^{-1}$ Eastman AQ55 ${ }^{\circledR}$ solution (diluted with water/acetone).

An elapsed time of 2-5 min was given before compression of the floating film, which was performed using $30 \mathrm{~mm} \mathrm{~min}^{-1}$ as barriers speed. On the basis of the shapes of relevant Langmuir isotherms, typical surface pressures for performing the LB deposition were $25 \mathrm{mN} \mathrm{m}^{-1}$ for Nafion ${ }^{\circledR}$ and Tosflex ${ }^{\circledR}$ and $18 \mathrm{mN} \mathrm{m}^{-1}$ for Eastman AQ55 ${ }^{\circledR}$.

\subsection{QCM and electrochemical measurements}

Quartz microbalance measurements were performed with an electrochemical microbalance, mod. QCA 917 (Seiko-EG\&G) with oscillator QCA 917-11 Seiko EG\&G. The frequency changes were measured by using $10 \mathrm{MHz}$ 
quartz crystals gold covered, characterized by a sensitivity of $0.2266 \mathrm{KHz} \mathrm{cm}^{2} \mu \mathrm{g}^{-1}$.

The electrochemical measurements were performed using a CHI model $620 \mathrm{~A}$ voltammetric analyzer, controlled by its software. A standard three electrodes cell configuration was used. The working electrodes (on which the LB films were deposited) were: indium-tin oxide (ITO, Delta Technologies, USA) coated glass plates, glassy carbon platelets (Tokay Carbon, Japan), quartz crystal coated with gold on which the LB films of ionomers were deposited. To increase the affinity of the electrode surface for the polymers, ITO electrodes were silanized by dipping for $10 \mathrm{~min}$ in a $5 \%$ dimethyldichlorosilane solution in $\mathrm{CCl}_{4}$; gold electrodes were alkylthiolated by dipping in $1 \mathrm{mM}$ dodecanethiol solution for $1 \mathrm{~h}$.

The LB coated electrodes were kept in the analyte solution for $10 \mathrm{~min}$ before recording the cyclic voltammograms shown in this paper. Preliminary tests showed, in fact, that the voltammetric signals of the analytes increased progressively soon after dipping the working electrode in the solution, until reaching a stable response after about $7-8 \mathrm{~min}$. In the electrochemical cell, the working electrode area in contact with the solution was kept equal to $0.07 \mathrm{~cm}^{2}$.

A platinum coil was the counter electrode and an $\mathrm{Ag} / \mathrm{AgCl}$ ( $\mathrm{KCl}$ saturated) was the reference electrode to which all potentials are referred. Solutions were de-aerated and kept under a nitrogen atmosphere during the measurements.

\section{Results and discussion}

\subsection{Langmuir isotherms}

Fig. 1 shows the surface pressure $(\Pi)$ versus trough area (A) isotherms of Nafion ${ }^{\circledR}$ molecules obtained in aqueous subphases of different composition. The $X$-axis plots the trough area instead of the area per molecule due to the fact that the exact solubility of Nafion ${ }^{\circledR}$ (and the other ionomers as well) in the different subphases is unknown. Moreover,

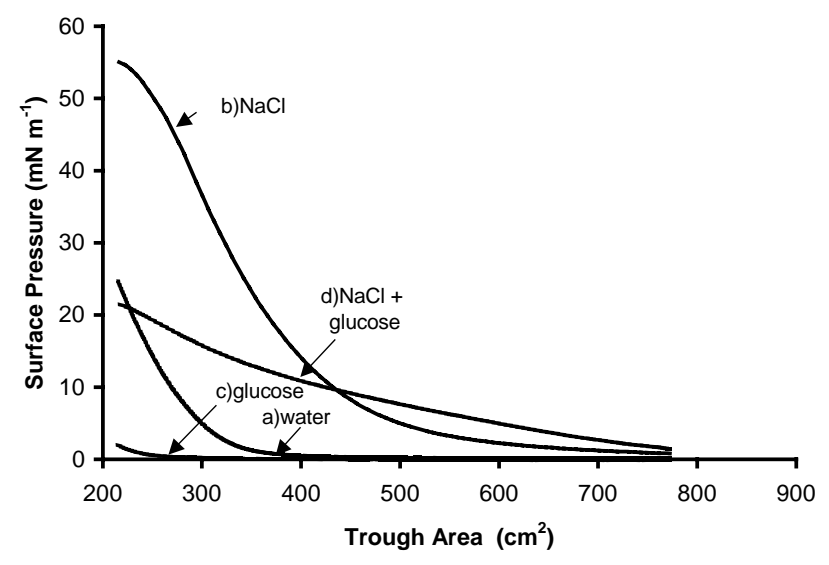

Fig. 1. Pressure-area $(\Pi-A)$ isotherms curves of $\mathrm{Nafion}^{\circledR}$ at different subphases: (a) $\mathrm{H}_{2} \mathrm{O}$, (b) $0.1 \mathrm{M} \mathrm{NaCl}$, (c) $0.5 \mathrm{M}$ glucose, and (d) $0.1 \mathrm{M}$ $\mathrm{NaCl}+0.5 \mathrm{M}$ glucose. since we are dealing with a polymeric material the area per molecule parameter should be correctly substituted by a area per monomeric unit value, which is a parameter of doubtful usefulness and definition, particularly for polymers which aggregate in domains, such as the studied ionomers [6].

Some of the features of the isotherms (a) and (b) in Fig. 1 have been described elsewhere [15], such as the lack of evident phase transitions when pure water is the subphase and the dramatic change in the shape of the isotherms when a strong electrolyte, such as $\mathrm{NaCl}$, is added to the subphase. This difference depends on the fact that, in the absence of dissolved salts, the sulfonic groups of Nafion ${ }^{\circledR}$ repel each other hindering the formation of a stable film at the air-water interface. On the other hand, the presence of dissolved $\mathrm{Na}^{+}$ cations minimizes these repulsive interactions because of the neutralization of the negative charges of the sulphonic groups. This interpretation is confirmed by the shape of the isotherms (c) and (d) in Fig. 1, obtained in subphases containing glucose or glucose and $\mathrm{NaCl}$, respectively. In both cases, the presence of glucose does not help the formation of a stable interfacial film. In particular, the comparison between curves (b) and (d) indicates that the lowering of the dielectric constant of the subphase caused by the addition of glucose lowers the shielding capability of $\mathrm{NaCl}$ aqueous solutions (curve b).

The $\Pi-A$ isotherms of AQ55 in aqueous subphases containing different electrolytes are shown in Fig. 2. Even if the AQ55 isotherms are flatter and characterized by less marked phase transitions than those of Nafion ${ }^{\circledR}$, their shapes shows some similarities with the trends observed for the latter. The isotherm obtained in pure water (curve a) is characterized by a flat shape with very low surface pressure values which even decrease while lowering the barrier distance. This agrees with the known good water solubility of AQ55 [25]. As shown for instance by curves (b)-(d), the addition of strong electrolytes changes the shape of the isotherms producing plots characterized by the increase in the surface pressure while lowering the barrier distance up to reaching maximum $\Pi$ values of about $22-23 \mathrm{mN} \mathrm{m}^{-1}$. This evidence indicates the formation of a stable monolayer at the air-water interface. Nevertheless, in the case of the AQ55 isotherms, the increase in surface pressure with increasing compression of the interfacial film is lower than the increase observed for Nafion ${ }^{\circledR}$, even in the presence of a cation characterized by a high charge/radius ratios, such as $\mathrm{La}^{3+}$ (see curve (d) in Fig. 2).

Fig. 3 shows the $\Pi-A$ isotherms of Tosflex ${ }^{\circledR}$ in different subphases. As in the case of Nafion ${ }^{\circledR}$, the isotherm of Tosflex ${ }^{\circledR}$ obtained in pure water (curve not shown) does not evidence the formation of a stable monolayer at the air-water interface. Again, the addition of strong electrolytes to the subphase changes drastically the shape of the isotherms. In general the isotherms obtained are quite similar to those observed in the case of Nafion ${ }^{\circledR}$ both as far as shape and maximum $\Pi$ values are concerned. This agrees with the similarity in the perfluorinated backbone skeleton present 


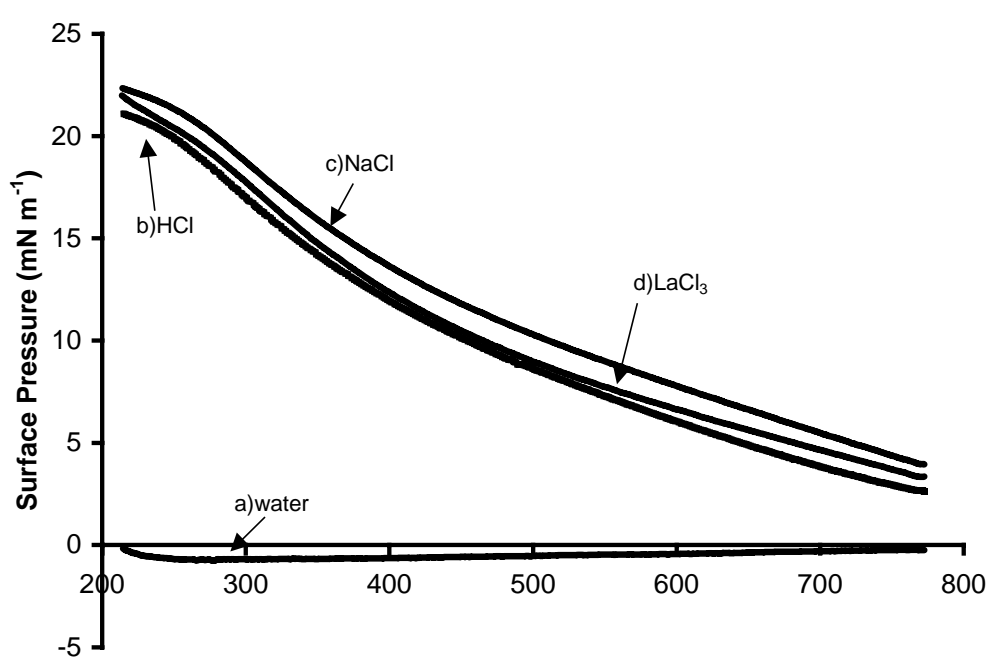

Trough Area $\left(\mathrm{cm}^{2}\right)$

Fig. 2. Pressure-area $(\Pi-A)$ isotherms curves of AQ55 at different subphases: (a) $\mathrm{H}_{2} \mathrm{O}$, (b) $10^{-2} \mathrm{M} \mathrm{HCl}$ (pH 2), (c) $0.1 \mathrm{M} \mathrm{NaCl}$, and (d) $0.01 \mathrm{M} \mathrm{LaCl}$.

both in Tosflex ${ }^{\circledR}$ and Nafion ${ }^{\circledR}$ structures (see Scheme 1). On the other hand, the fact that Tosflex ${ }^{\circledR}$ is an anion exchanger while Nafion ${ }^{\circledR}$ is a cation exchanger reflects in the evidence that, for Tosflex ${ }^{\circledR}$, the successful compression of the interfacial film depends on the nature of the anions added to the subphase. The comparison between the isotherms in Fig. 3 indicates that the condensation degree of the interfacial film scales in the order $\mathrm{Fe}(\mathrm{CN})_{6}^{3-}>\mathrm{SO}_{4}^{2-}>\mathrm{COO}^{-}>$ $\mathrm{NO}_{3}^{-}>\mathrm{Cl}^{-}>\mathrm{CH}_{3} \mathrm{COO}^{-}$. Interestingly, this sequence parallels the sequence of the ion-exchange selectivity of anion exchangers [27] so suggesting that the same factor (namely charge/radius ratio) rules both $\mathrm{LB}$ films condensation and ion-exchange selectivity of Tosflex ${ }^{\circledR}$.

\section{2. $L B$ deposition and $Q C M$ measurements}

Preliminary experiments showed that LB deposition of ionomer films gave more reproducible results onto hy-

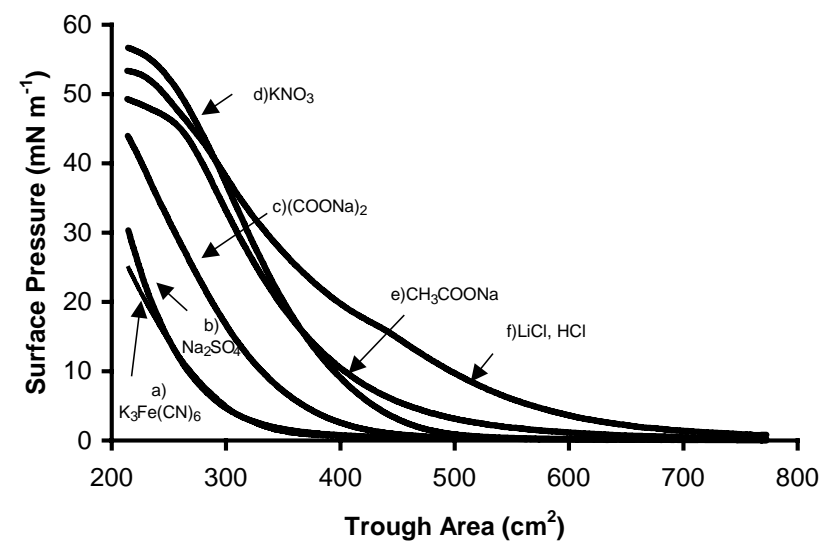

Fig. 3. Pressure-area $(\Pi-A)$ isotherms curves of Tosflex ${ }^{\circledR}$ at different subphases: (a) $10^{-4} \mathrm{M} \mathrm{K}_{3} \mathrm{Fe}(\mathrm{CN})_{6}$, (b) $0.1 \mathrm{M} \mathrm{Na}_{2} \mathrm{SO}_{4}$, (c) $0.1 \mathrm{M}(\mathrm{COONa})_{2}$, (d) $0.1 \mathrm{M} \mathrm{KNO}_{3}$, (e) $0.1 \mathrm{M} \mathrm{CH}_{3} \mathrm{COONa}$, and (f) $0.1 \mathrm{M} \mathrm{LiCl}, 10^{-2} \mathrm{M} \mathrm{HCl}$. drophobic substrates such as glassy carbon, silanized ITO or alkylthiolated gold (see experimentals).

The efficiency of the LB deposition for the three different ionomers here examined was studied by QCM measurements, using a $10 \mathrm{MHz}$ quartz oscillator with gold electrodes precoated by a monolayer of dodecanethiol.

Fig. 4A and $\mathrm{B}$ show that the oscillation frequency of the crystal decreases following trends which are linear with the number of layers deposited for the two perfluorinated ionomers examined here, i.e. Nafion ${ }^{\circledR}$ and Tosflex ${ }^{\circledR}$.

For AQ 55, data shown in Fig. 5A indicate that when the deposition is performed using $\mathrm{NaCl}$ solution as the subphase, frequency changes display a quite random and not linear dependence on the number of deposition steps performed, so indicating severe problems in the transfer of the interfacial film under such experimental conditions. The situation changes significantly when the subphase contains a trivalent cation such as $\mathrm{La}^{3+}$.

Fig. 5B shows, in this case, a change in frequency which increases linearly with the number of deposition steps performed, apart a first jump after the first deposition step with which a higher mass is transferred than in the following steps. Although the isotherms shown in Fig. 2 do not change too much when passing from $\mathrm{Na}^{+}$to $\mathrm{La}^{3+}$, however, the presence of the trivalent cation shows to be crucial for the successful transfer of the film. This can be explained taking into account that $\mathrm{La}^{3+}$ is a multiply charged cation which can crosslink electrostatically different polymer chains [28], so stabilizing the film during the delicate deposition step.

By using the Sauerbray equation [29], frequency changes measured by the QCM were converted into mass changes. Relevant typical data are reported in Table 1.

These data show that the mass per layer deposited in the cases of Nafion ${ }^{\circledR}$ and Tosflex ${ }^{\circledR}$ is much lower than for AQ55. This agrees with the deposition, for the two perflourinated ionomers, of ultrathin films made by a basic 


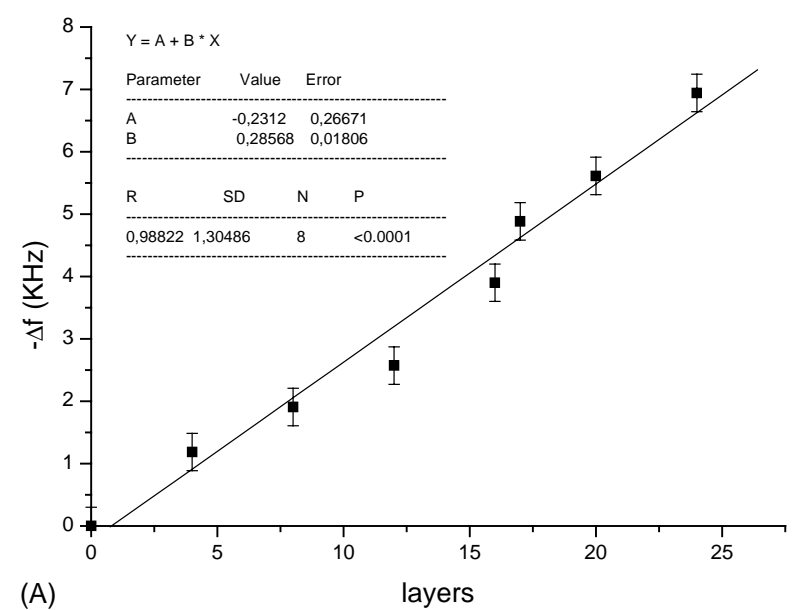

(A)

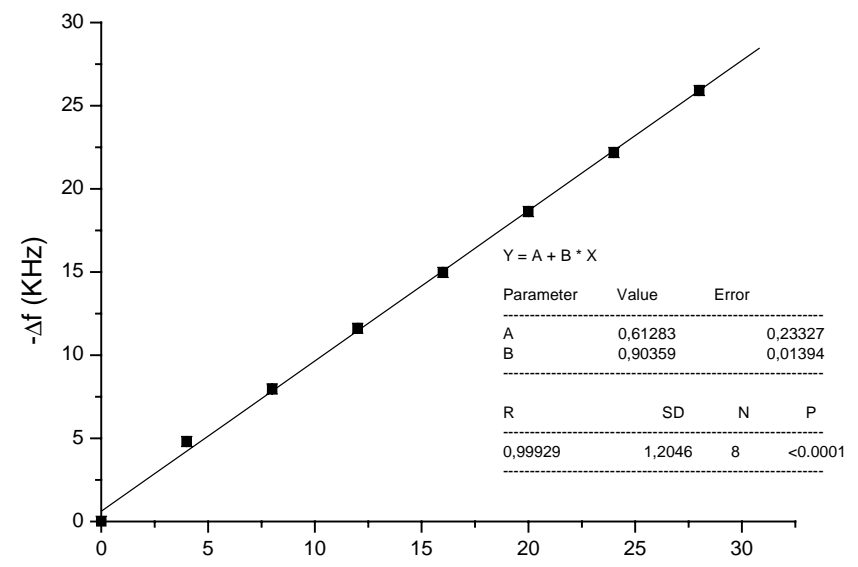

(B)

layers

Fig. 4. Frequency changes measured by QCM during Langmuir-Blodgett deposition experiments performed on a gold covered $10 \mathrm{MHz}$ quartz crystal, pretreated with dodecanethiol, as a function of the number of deposition steps. (a) Nafion ${ }^{\circledR}$, subphase $0.1 \mathrm{M} \mathrm{NaCl}$ and (b) Tosflex, subphase $0.1 \mathrm{M} \mathrm{KCl}$.

structure closer to an ordered 2D monolayer (see below) than the film obtained with AQ55, which seems to keep a 3D multi-layered structure even after compression in the trough.

Table 1

Mass changes measured by QCM during Langmuir-Blodgett deposition experiments performed on a gold covered $10 \mathrm{MHz}$ quartz crystal, pretreated with dodecanethiol, as a function of the number of deposition steps

\begin{tabular}{lclc}
\hline $\begin{array}{l}\text { Number of deposition } \\
\text { steps (layers) }\end{array}$ & \multicolumn{3}{l}{ Mass deposited $\left(\mu \mathrm{g} \mathrm{cm}^{-2}\right)$} \\
\cline { 2 - 4 } & Nafion $^{\circledR a}$ & Eastman AQ 55 & Tosflex ${ }^{\circledR \mathrm{c}}$ \\
\hline 4 & 5.25 & 21.23 & 6.70 \\
8 & 8.43 & 35.18 & 10.36 \\
12 & 11.34 & 51.25 & 14.64 \\
\hline
\end{tabular}

a Subphase: $0.1 \mathrm{M} \mathrm{NaCl}$, deposition at surface pressure of $25 \mathrm{mN} \mathrm{m}^{-1}$.

b Subphase: $0.01 \mathrm{M} \mathrm{LaCl}$, deposition at surface pressure of $18 \mathrm{mN} \mathrm{m}^{-1}$.

${ }^{c}$ Subphase: $0.1 \mathrm{M} \mathrm{KCl}$, deposition at surface pressure of $25 \mathrm{mN} \mathrm{m}^{-1}$.
From the known density of recasted AQ55 $\left(1.34 \mathrm{~g} \mathrm{~cm}^{-2}\right.$ after drying, [30]) one can get a rough estimate of the film thickness for the thicker coating in Table 1 (namely, 12 layers of AQ55) which results about $382 \mathrm{~nm}$. Note that this is lower than the maximum thickness $(600 \mathrm{~nm})$ usually considered acceptable for the application of the Sauerbray equation [29].

The evidence that mass changes for Tosflex ${ }^{\circledR}$ are slightly higher than those observed for Nafion ${ }^{\circledR}$ agrees with the higher equivalent weight of the former $(\mathrm{EW}=1850$ for Tosflex ${ }^{\circledR}[22]$ versus EW $=1100$ for Nafion ${ }^{\circledR}$ ).

It is interesting to discuss briefly data in Table 1 to the aim of understanding how close or far is the structure of the LB polymer films from what can be imagined as a "monolayer" of a ion-exchange polymer. This can be done for Nafion ${ }^{\circledR}$, for which density and equivalent weight values are known. The ratio between equivalent weight (1100) and density $\left(2 \mathrm{~g} \mathrm{~cm}^{-3}\right.$ for "dry" Nafion $\left.{ }^{\circledR}[6]\right)$ gives the volume occupied by one equivalent of ion-exchange units (namely, $550 \mathrm{~cm}^{3}$ ) which divided by the Avogadro number $(N)$ gives a volume of $0.9 \times 10^{-21} \mathrm{~cm}^{3}$ per ion-exchange unit (on a molecular basis). By assuming a very simplified model in which each ion-exchange unit occupies a cubic portion of space, it is possible to estimate that each ion-exchange site should cover an area section of about $10^{-14} \mathrm{~cm}^{2}$. Therefore, if all ion-exchange sites be distributed one close to the other in a sort of a 2D "tiled floor" of sulphonic groups, the number of ion-exchange sites should be around $10^{14}$ sites $\mathrm{cm}^{-2}$. According to Table 1, the surface coverage of ion-exchange units in one LB Nafion ${ }^{\circledR}$ layer (IEN) is given as:

$\mathrm{IEN}=\frac{\operatorname{mass} \times N}{\text { layers } \times \mathrm{EW}}$

and results $7.2 \times 10^{14}$ ion-exchange sites $\mathrm{cm}^{-2}$.

This figure is only slightly higher than the value estimated for the "monolayer"; this is a quite interesting result if one thinks that we are trying to make a "flat floor" from a big and entangled polymer mass and not by assembling together single molecular tiles.

\subsection{Ion-exchange voltammetry}

In order to investigate and compare the preconcentration capabilities and ion-exchange voltammetric behavior of Nafion ${ }^{\circledR}$ and AQ55 LB films (both cation exchangers), we exploited, at first, the $\mathrm{FA}^{+}$cation as electroactive probe.

Fig. 6 shows the CV patterns recorded at different scan rates at an ITO electrodes coated with 30 Nafion ${ }^{\circledR}$ LB films, dipped in $10^{-5} \mathrm{M} \mathrm{FA}^{+}$solution. The $\mathrm{CV}$ patterns show the typical features relevant to the one electron reversible oxidation of $\mathrm{FA}^{+}$. Note that, at an uncoated ITO dipped in the same (rather diluted) $\mathrm{FA}^{+}$solution, no relevant $\mathrm{FA}^{+}$signal is detected. For the LB coated electrodes, the typical FA ${ }^{+}$ signal is retained (even if slightly lower) also after transfer into pure supporting electrolyte. These evidences indicate an efficient ion-exchange preconcentration of $\mathrm{FA}^{+}$in the $\mathrm{LB}$ 

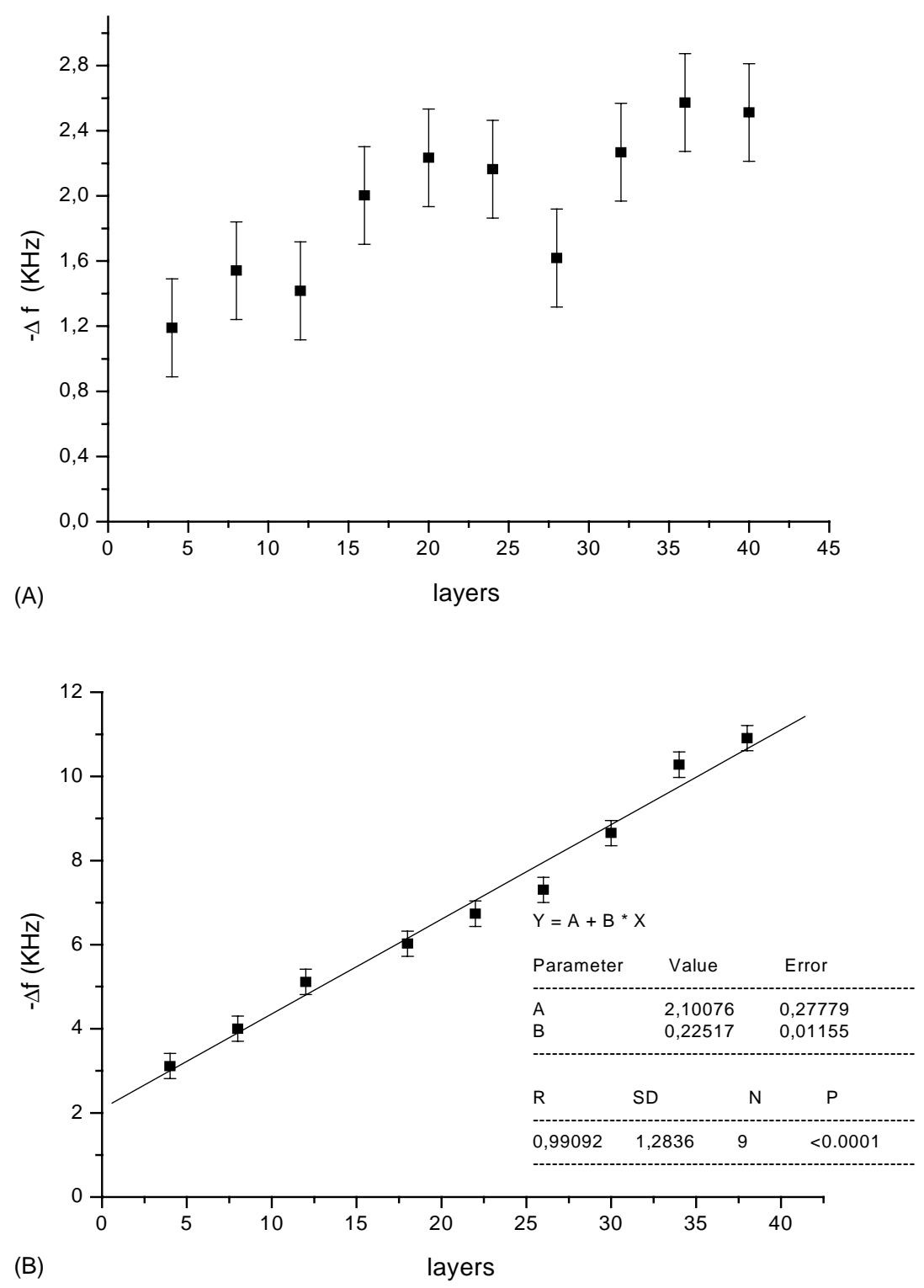

Fig. 5. Frequency changes measured by QCM during Langmuir-Blodgett deposition experiments performed on a gold covered $10 \mathrm{MHz}$ quartz crystal, pretreated with dodecanethiol, as a function of the number of deposition steps. (a) $\mathrm{AQ55}$, subphase $0.1 \mathrm{M} \mathrm{LiClO}_{4}$ and (b) $\mathrm{AQ} 55$, subpahse $0.01 \mathrm{M} \mathrm{LaCl}$.

coatings with the observed signals being due to $\mathrm{FA}^{+}$incorporated by ion-exchange in the coating. Peak currents $\left(I_{\mathrm{p}}\right)$ display a linear dependence on the scan rate scan rate $(v)$ for $v \leq 50 \mathrm{mV} \mathrm{s}^{-1}$ and on $v^{1 / 2}$ at higher scan rates. These evidences together with the shape parameters of the CVs in Fig. 6, indicate a thin layer behavior for $v=50 \mathrm{mV} \mathrm{s}^{-1}$ and planar diffusion control at higher scan rate. Such a transition between different transport regimes at polymer coated electrodes is observed at the scan rate at which the thickness of the diffusion layer (which decreases with increasing $v$ ) becomes comparable with the thickness of the coating $[11,21]$. These data agrees with a rather small thickness of the Nafion ${ }^{\circledR}$ LB coating [15,21], which can be estimated around $100-150 \mathrm{~nm}$ for the 30 layers film, as measured by AFM for Nafion ${ }^{\circledR}$ LS coatings [15].
A similar behavior is observed also at an AQ55 LB coated ITO dipped in the same solution, even if in this case the scan rate transition is observed at about $80 \mathrm{mV} \mathrm{s}^{-1}$. This agrees with a higher thickness for the AQ55 coating after wetting by the electrolyte solution. For instance, the thickness of a film made of 12 LB layers of AQ55 at the dry state was estimated to be approximately $382 \mathrm{~nm}$ (see above, QCM data), while for the same film, but in wet conditions this thickness is expected to increase of $70 \%$ [30], i.e. to become about $650 \mathrm{~nm}$.

Also other redox probes, such as $\mathrm{Ru}\left(\mathrm{NH}_{3}\right)_{6}{ }^{3+}$, when incorporated by AQ55 LB coatings give voltammetric patterns with features typical for species ion-exchanged in thin coatings. Peak currents are, in fact, higher than those measured at bare electrodes and they increase with the number 


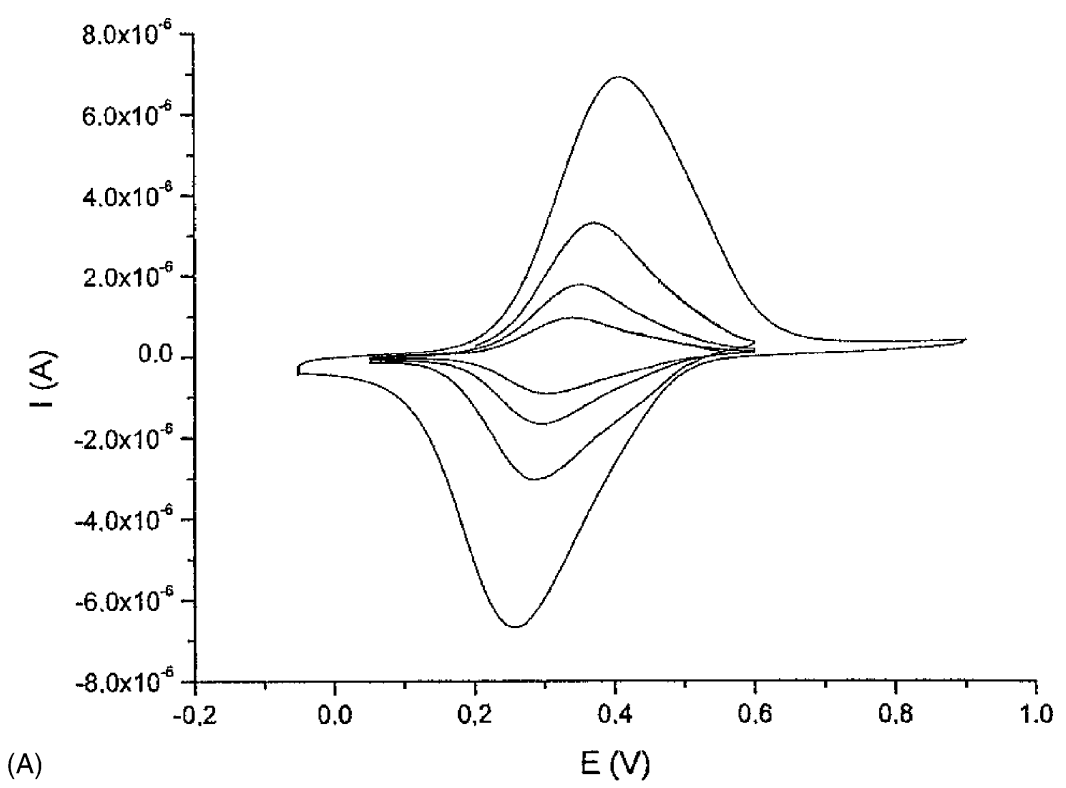

(A)

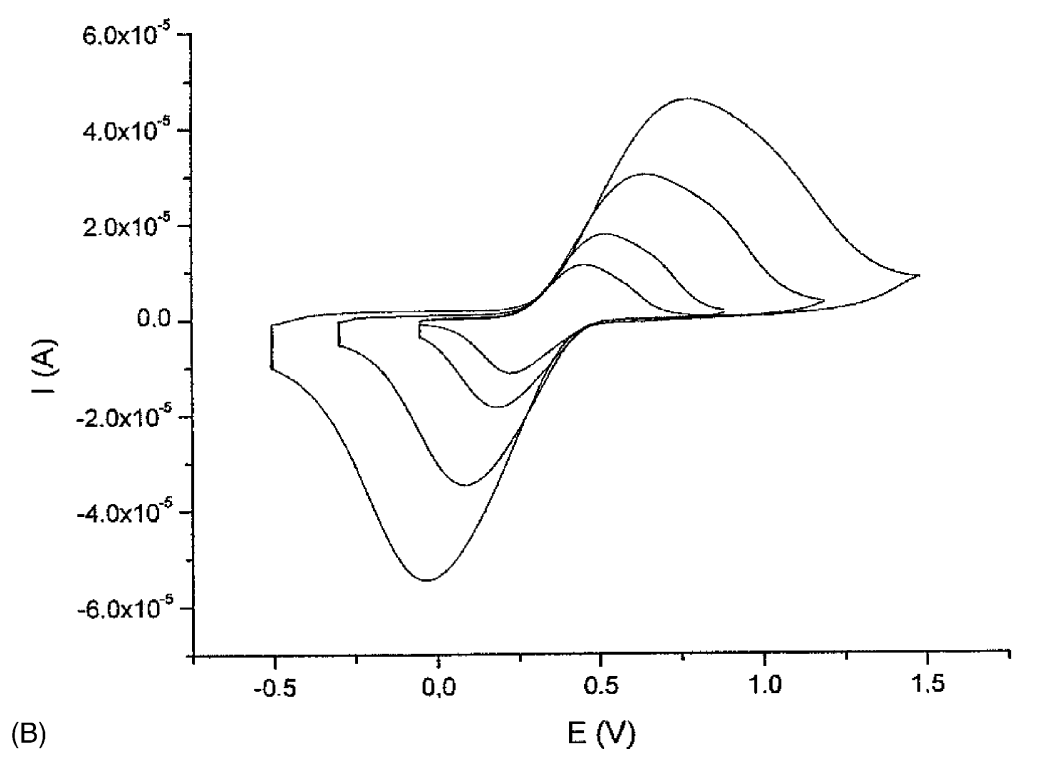

Fig. 6. (A) Cyclic voltammograms recorded at an ITO coated with 30 Nafion ${ }^{\circledR} \mathrm{LB}$ films in $10^{-5} \mathrm{M} \mathrm{FA}^{+}$solution, $10^{-2} \mathrm{M} \mathrm{NaNO}_{3}$ solution. Scan rates: (A) $5,10,20,50 \mathrm{mV} \mathrm{s}^{-1}$; (B) $0.070,0.100,0.200,1.000 \mathrm{~V} \mathrm{~s}^{-1}$.

of layers deposited; a thin layer behavior is observed at low scan rates [11]. With this probe we examined also the influence of the surface pressure during the deposition. AQ55 LB coatings transferred on ITO using very low surface pressures (namely, $2.5 \mathrm{mN} \mathrm{m}^{-1}$ ) give $\mathrm{CVs}$ characterized by diffusion controlled behavior which changes into a thin layer behavior only at very low scan rates $\left(5 \mathrm{mV} \mathrm{s}^{-1}\right)$ This contrasts with what is observed for films deposited at high surface pressures $\left(18 \mathrm{mN} \mathrm{m}^{-1}\right)$ which display thin layer behavior up to $200 \mathrm{mV} \mathrm{s}^{-1}$ (for $\mathrm{Ru}\left(\mathrm{NH}_{3}\right)_{6}{ }^{3+}$ ). Moreover, peak currents at e.g. $100 \mathrm{mV} \mathrm{s}^{-1}$ are lower for the AQ55 film deposited at low surface pressure than those recorded at ITO coated with films deposited at high surface pressure $\left(18 \mathrm{mN} \mathrm{m}^{-1}\right)$. These results indicate a lower thickness, but a higher ion-exchange capacity (that is a higher number of ion-exchange sites per volume unit) for the "compressed" coating, in agreement with a packing of the interfacial film during the Langmuir compression.

The ion-exchange voltammetric characteristics of Tosflex ${ }^{\circledR}$ LB films were investigated by using $\left[\mathrm{Fe}(\mathrm{CN})_{6}\right]^{3-}$ as the electroactive anion probe. Fig. 7A shows the $\mathrm{CV}$ recorded at $50 \mathrm{mV} \mathrm{s}^{-1}$ at an ITO coated with 10 Tosflex ${ }^{\circledR}$ LB layers and dipped in $10^{-5} \mathrm{M}\left[\mathrm{Fe}(\mathrm{CN})_{6}\right]^{3-}$ solution. The main voltammetric features indicate that the observed signal is due to the one-electron reduction of $\left[\mathrm{Fe}(\mathrm{CN})_{6}\right]^{3-}$ incorporated by ion-exchange in the coating. In spite the small number of layers deposited (namely, 10), peak currents always show a linear dependence on the square 


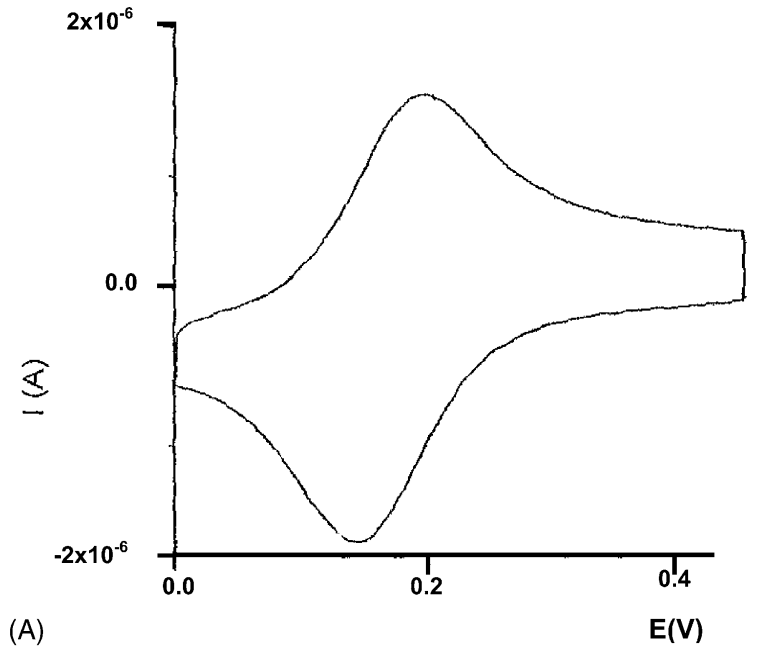

(A)

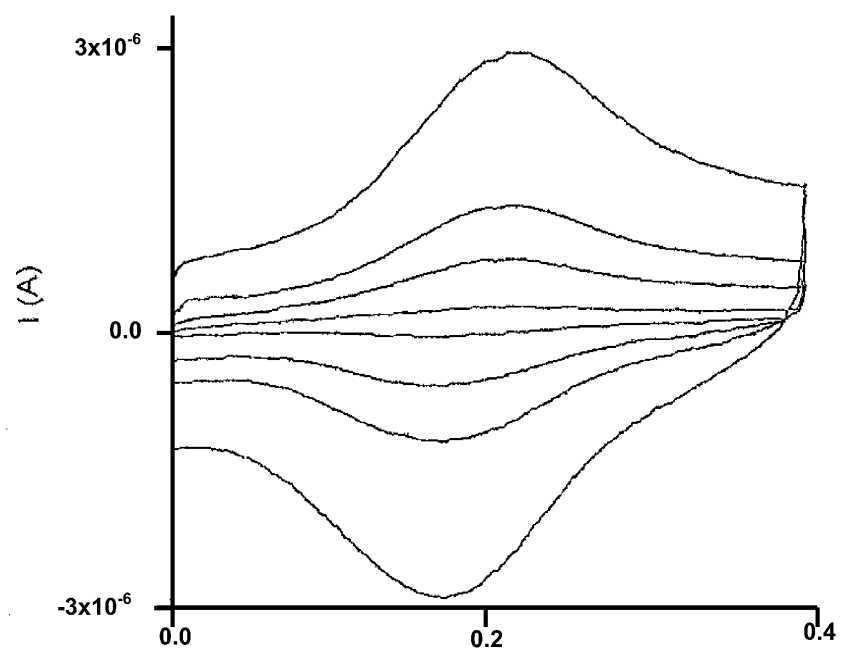

(B)

$E(V)$

Fig. 7. (A) Cyclic voltammogram recorded at an ITO coated with 10 Tosflex ${ }^{\circledR} \mathrm{LB}$ films in $10^{-5} \mathrm{M}\left[\mathrm{Fe}(\mathrm{CN})_{6}\right]^{3-}, 10^{-2} \mathrm{M} \mathrm{NaCl}$ solution at $50 \mathrm{mV} \mathrm{s}^{-1}$. (B) Cyclic voltammograms recorded at an ITO coated with 10 Tosflex ${ }^{\circledR}$ LB deposited in a subphase containing $10^{-4} \mathrm{M}\left[\mathrm{Fe}(\mathrm{CN})_{6}\right]^{3-}$; scan rates $5,10,20,50 \mathrm{mV} \mathrm{s}^{-1}$, supporting electrolyte as in (A).

root of the scan rate indicating a diffusion controlled behavior.

This suggests that the apparent diffusion coefficient for $\left[\mathrm{Fe}(\mathrm{CN})_{6}\right]^{3-}$ ions incorporated in the Tosflex ${ }^{\circledR} \mathrm{LB}$ coating is smaller than that for $\mathrm{FA}^{+}$cation incorporated in Nafion ${ }^{\circledR}$ LB coatings [11]. Note that the precise measurement of $D_{\text {app }}$ values would require the exact knowledge of the wet film thickness obtained by "in situ" measurements, for instance, by ellipsometry. However, a detailed study of this problem is beyond the goals of the present paper.

The CVs reported in Fig. 7B show that $\mathrm{Fe}(\mathrm{CN})_{6}{ }^{3-}$ can be incorporated in the coating also during the fabrication of the LB films, by prior dissolution of the electroactive cation directly in the subphase. The shape of the CVs and the analysis of peak current dependence on $v$ (linear for $v=$ $100 \mathrm{mV} \mathrm{s}^{-1}$ ) indicates, for this case, a thin layer behavior up to such a relatively high scan rate. This agrees with the higher condensation degree which characterizes the Langmuir isotherm obtained when $\mathrm{Fe}(\mathrm{CN})_{6}{ }^{3-}$ is dissolved in the subphase and evidenced in Fig. 3. The voltammetric signal relevant to the incorporated redox probe remains almost unchanged after several hours of dipping in pure supporting electrolyte.

The possibility to prepare electroactive LB coating by premixing ionomers and redox ions (dissolved in the subphase) can open interesting prospects for the preparation of electrodes modified by ultrathin electroactive films containing redox molecules useful for their electrocatalytic and/or electron shuttling (mediator) properties as the redox probes studied in the present work.

\section{Conclusions}

This work evidenced the possibility of using the Langmuir-Blodgett technique to prepare ultrathin films of different ionomers and to transfer them by LB deposition onto electrode surfaces. The choice of a suitable strong electrolyte dissolved in the subphase is crucial for the successful preparation of stable ionomer LB films. As far as stability and condensation degree are concerned, perfluorinated polymers such as Nafion ${ }^{\circledR}$ and Tosflex ${ }^{\circledR}$ showed better properties than the polyester sulphonated Eastman AQ55 ${ }^{\circledR}$, the former being useable for many days of ion-exchange voltammetric measurements. Electrodes modified with LB films of ionomers showed ion-exchange-preconcentration capabilities useful for ion-exchange voltammetric applications.

Because of the polymeric nature of the ionomers, the films obtained, although characterized by a 2D packing and ordering (more relevant for the perfluorinated ionomers) do not achieve a complete spreading of the ion-exchange sites on a 2D "monomolecular" sheet, but tend to achieve a sort of flattened-entangled structure.

Further studies on the possible use of such films for the controlled immobilization of catalysts, biocatalysts or molecules containing specific molecular recognition sites as well as on the changes of the surface properties of the coated electrodes on the number of deposition steps or chemical nature of incorporated redox ions are presently in progress.

\section{Acknowledgements}

This research was supported by MIUR (Rome).

\section{References}

[1] I. Langmuir, V.J. Schaefer, J. Am. Chem. Soc. 57 (1938) 1007.

[2] M. Petty, Langmuir-Blodgett Films, Cambridge University Press, Cambridge, 1996.

[3] A. Ulman, Ultrathin Organic Films, Academic press, New York, 1991. 
[4] R. Bilewicz, M. Majda, J. Am. Chem. Soc. 113 (1991) 5464.

[5] B. Lindholm-Sethson, Langmuir 12 (1996) 3305.

[6] R.S. Yeo, H.L. Yeager, in: B.E. Conway, R.E. White, J.O'M. Bockris (Eds.), Modern Aspects of Electrochemistry, vol. 16, Plenum Press, New York, 1985, p. 437.

[7] B. Xing, O. Savadogo, Electrochem. Commun. 2 (2000) 697.

[8] D.A. Buttry, F.C. Anson, J. Electroanal. Chem. 130 (1981) 333.

[9] H.S. White, J. Leddy, A.J. Bard, J. Am. Chem. Soc. 104 (1982) 4811.

[10] C.R. Martin, K.A. Dollard, J. Electroanal. Chem. 159 (1983) 126.

[11] P. Ugo, L.M. Moretto, Electroanalysis 7 (1995) 1105.

[12] P. Ugo, L.M. Moretto, F. Vezza', Chem. Phys. Chem. 3 (2002) 917.

[13] C.M.A. Brett, D.A. Fungaro, J.M. Morgado, M.H. Gil, J. Electroanal. Chem. 468 (1999) 26.

[14] E. Sabatani, H.D. Nikol, H.B. Gray, F.C. Anson, J. Am. Chem. Soc. 118 (1996) 1158.

[15] P. Bertoncello, M.K. Ram, A. Notargiacomo, P. Ugo, C. Nicolini, Phys. Chem. Chem. Phys. 4 (2002) 4036.

[16] B. Brunetti, P. Ugo, J. Electroanal. Chem. 460 (1999) 38.

[17] J. Weber, P. Janda, L. Kavan, A. Jegorov, J. Electroanal. Chem. 200 (1986) 379.
[18] R.B. Moore III, C.R. Martin, Macromolecules 21 (1988) 1334.

[19] K.A. Striebel, G.G. Scherer, O. Haas, J. Electroanal. Chem. 304 (1991) 289.

[20] M. Shi, F.C. Anson, J. Electroanal. Chem. 415 (1996) 41.

[21] P. Bertoncello, P. Ugo, J. Braz. Chem. Soc. 14 (2003) 517.

[22] L.M. Moretto, G.A. Mazzocchin, P. Ugo, J. Electroanal. Chem. 427 (1997) 113

[23] L. Dunsch, L. Kavan, J. Weber, J. Electroanal. Chem. 280 (1990) 313.

[24] F. Nguyen, F.C. Anson, Electrochim. Acta 44 (1998) 247.

[25] T. Gennett, W.C. Purdy, Anal. Chem. 62 (1990) 2155.

[26] A. Lombardo, T.I. Bieber, J. Chem. Educ. 60 (1983) 1080.

[27] F. Helfferich, Ion Exchange, McGraw-Hill, New York, 1962, p. 168.

[28] N. Oyama, T. Ohsaka, M. Kaneko, K. Sato, H. Matsuda, J. Am. Chem. Soc. 105 (1983) 6003.

[29] D. Buttry, in: A.J. Bard (Ed.), Electroanalytical Chemistry, vol.17, Marcel Dekker, New York, 1991, p. 1.

[30] P. Ugo, L.M. Moretto, S. Bellomi, V.P. Menon, C.R. Martin, Anal. Chem. 68 (1996) 4160. 